\title{
Photo-excited electroless deposition of semiconducting oxide thin films and their electrocatalytic properties
}

\author{
Kai Kamada* and Ayano Moriyasu \\ Received (in $X X X, X X X)$ Xth $X X X X X X X X X 200 X$, Accepted Xth $X X X X X X X X X 200 X$ \\ First published on the web $X$ th $X X X X X X X X X 200 X$ \\ DOI: $10.1039 / b 000000 x$
}

The present study demonstrates the beneficial effects of ultraviolet (UV) light irradiation on the electroless deposition of several n-type semiconducting oxide thin films from an aqueous solution. To obtain ceria $\left(\mathrm{CeO}_{2}\right), \mathrm{Ce}^{3+}$ was oxidized to a higher valence in the presence of dissolved oxygen molecules, and was then precipitated as $\mathrm{CeO}_{2}$ on a conductive substrate through a local cell mechanism. Irradiation of the substrate by UV light during the reaction caused the generation of photocarriers (electron and holes) in the surface oxide layer. The resultant photocarriers enabled further electrochemical reactions on the surfaces of pre-deposited $\mathrm{CeO}_{2}$ nuclei together with the substrate surface. As a result, the deposition rate and crystallinity of the film were significantly improved by the UV light irradiation. $\mathrm{CeO}_{2}$ thin films prepared on a Pt substrate by the proposed photoelectroless deposition method showed an electrocatalytic activity for methanol oxidation without post-annealing, in contrast to the lower activity of a film deposited in the dark. This discrepancy is discussed on the basis of film morphology and crystallinity. Furthermore, it was confirmed that electroless deposition of Sn and Pr oxide (hydroxide) was also accelerated by photoirradiation. In this paper, the photoelectroless deposition mechanism is discussed in detail, and the advantages of the proposed techniques are clarified.

\section{Introduction}

Since inorganic materials can interact with photons in various ways, a number of practical applications including energy conversion (e.g., solar cells), chemical conversion (e.g., photocatalysts), and surface morphology control (e.g., laser micromachining) have been developed. In general, processes based on photon irradiation are performed under clean, environmentally-friendly conditions. In researching the photoelectrochemistry of inorganic semiconductors, ${ }^{1}$ much attention has been devoted to hydrogen gas production as a new energy source, and to the purification of polluted emissions using semiconductor photocatalysts. Recently, photon energy has also been employed for the development of functional inorganic materials and improvement of their properties. For example, precise particle size control of semiconductor nanoparticles by wavelength-dependent photocorrosion, ${ }^{2}$ local electrochemical reactions by siteselective photon irradiation, ${ }^{3}$ and photoelectrochemical etching of single-crystal or polycrystalline semiconductor electrodes $^{4,5}$ have been reported in the past decade. The utilization of photon energy for the fabrication of functional inorganic materials offers numerous advantages, such as position-selective excitation using focused light, energy selectivity by wavelength, and the promotion of homogeneous reactions, especially in the liquid phase. That is, photoelectrochemical processes can induce various reactions that are otherwise difficult to achieve.

Several research groups, ours included, have studied the effects of photoirradiation during the electrochemical deposition of thin films in solution. ${ }^{6,7}$ In our previous paper, ${ }^{8}$ the photoelectrochemical deposition of iron(III) oxyhydroxide thin films from an $\mathrm{Fe}^{2+}$ solution induced the formation of unique nanostructures. As is well known, electrochemical processes in a solution system can bring about the formation of various oxide semiconductor films on a substrate. In particular, electroless deposition is recognized as a facile technique that can lead to film growth by simple immersion of the desired substrate, without requiring an external bias. However, there are several disadvantages associated with oxide film deposition: (1) a slow diffusion-controlled reaction rate, and (2) poor crystallinity, density, and adhesion of the films without post-treatment. Moreover, film growth via electrochemical reactions is inhibited after the substrate is covered by the deposited oxide layer, which has a relatively low conductivity. It is believed that photoirradiation can effectively circumvent these problems during the electroless deposition of oxide semiconductors. Under light irradiation, the electrochemical reactions are stimulated by the generation of photocarriers (electrons and holes) in the band structure of a deposit formed in advance, which reacts with the redox species at the deposit / solution interface. Accordingly, continuous growth of oxide films can be achieved under illumination, presumably enhancing their density and crystallinity.

Among many semiconducting oxides, ceria $\left(\mathrm{CeO}_{2}, E_{g} \sim 3.1\right.$ $\mathrm{eV}$ ) thin films have many attractive characteristics, such as ion-conducting, ${ }^{9}$ sun-screening, ${ }^{10}$ anti-corrosion, ${ }^{11}$ and electrocatalytic properties. ${ }^{12}$ Hence, the development of a facile solution-based method for attaining high-quality ceria thin films is an issue of great urgency. In the present paper, we demonstrate that photoirradiation during the electroless deposition of ceria thin films improves their growth rate, film 
density, and adhesion by influence of the photocarriers produced in the film, and the photodeposited films have a high electrocatalytic activity for the oxidation of methanol without post-annealing. In addition, the positive effects of photoirradiation for other oxides ( $\mathrm{Pr}$ and $\mathrm{Sn}$ ) are demonstrated. Thus, the proposed technique is a promising method for the fabrication of semiconductor oxide thin films. The success of the present technique may explore a novel aspect with respect to utilization of photon energy.

\section{Experimental}

Photoelectroless deposition was performed in a quartz glass beaker equipped with a water jacket to control the bath temperature. The solution for $\mathrm{CeO}_{2}$ deposition contained identical amounts of $\mathrm{Ce}\left(\mathrm{CH}_{3} \mathrm{COO}\right)_{3}$ and $\mathrm{CH}_{3} \mathrm{COOH}(0.05 \sim$ $0.20 \mathrm{M}$ ), and the $\mathrm{pH}$ of the solution was adjusted to 5.6 by the addition of a minute amount of $3 \mathrm{M} \mathrm{NaOH}$. To perform the electroless deposition, a Pt substrate was immersed in a solution at $293 \sim 313 \mathrm{~K}$ for up to $24 \mathrm{~h}$. During the reaction, the substrate was exposed to light from a $300 \mathrm{~W}$ Xe lamp. For comparison, a dark electroless deposition was also performed, in a beaker covered with aluminum foil. The open-circuit potential of the $\mathrm{Pt}$ substrate was monitored against a saturated $\mathrm{Ag} \mid \mathrm{AgCl}$ reference electrode. The deposition weight was recorded using a quartz crystal microbalance (QCM) method employing a $9 \mathrm{MHz}$ AT-cut quartz with $\mathrm{Pt}$ or $\mathrm{C}$ deposited on both sides. Inductively coupled plasma (ICP) analysis was carried out to determine the deposition amount of $\mathrm{Ce}$ after dissolving the film in a concentrated $\mathrm{H}_{2} \mathrm{SO}_{4}$ solution. The morphology and crystal structure of the as-deposited films were investigated using scanning electron microscopy (SEM), X-ray diffraction (XRD), and Raman spectroscopy. The electrocatalytic performance of the Pt substrate covered with a $\mathrm{CeO}_{2}$ film was evaluated by anodic polarization in $5 \mathrm{M}$ $\mathrm{CH}_{3} \mathrm{OH}+0.1 \mathrm{M} \mathrm{K}_{2} \mathrm{SO}_{4}$ solution using $\mathrm{Ag} \mid \mathrm{AgCl}$ and $\mathrm{Pt}$ as the reference and counter electrodes, respectively. The potential scan was performed with a scan rate of $10 \mathrm{mVs}^{-1}$. In order to deposit $\mathrm{Pr}$ or $\mathrm{Sn}$ oxide, the Pt substrate was immersed in a $0.05 \mathrm{M} \mathrm{Pr}\left(\mathrm{CH}_{3} \mathrm{COO}\right)_{3}+0.05 \mathrm{M} \mathrm{CH}_{3} \mathrm{COOH}(\mathrm{pH} \sim 7$ at $313 \mathrm{~K})$ or $0.05 \mathrm{M} \mathrm{SnSO}_{4}+1 \mathrm{M} \mathrm{H}_{2} \mathrm{SO}_{4}$ solution under UV light irradiation at $293 \mathrm{~K}$.

\section{Results and discussion}

Formation of transparent thin films showing interference colour was observed after electroless deposition at $313 \mathrm{~K}$ for $24 \mathrm{~h}$ in a mixed solution containing $0.05 \mathrm{M} \mathrm{Ce}\left(\mathrm{CH}_{3} \mathrm{COO}\right)_{3}$ and $0.05 \mathrm{M} \mathrm{CH}_{3} \mathrm{COOH}(\mathrm{pH}=5.6)$, irrespective of the light illumination. However, the color of the films was strongly dependent on the illumination, with blue films being produced in the presence of light, and yellow films in the absence of light. This discrepancy reflected either the deposition amount or the film thickness. Fig. 1a shows time evolutions of the deposition weight on $\mathrm{Pt}$, as estimated from QCM measurements. In each case, the deposition weight increased monotonically with reaction time. The simple relationship between the amount deposited and the deposition time suggests a facile control over the deposition
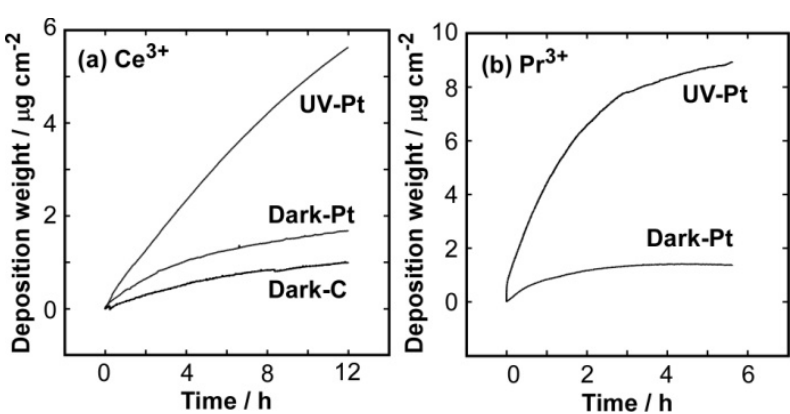

Fig. 1 Variation in the deposition weight on $\mathrm{Pt}$ or $\mathrm{C}$ substrates during electroless deposition under illumination or in the dark, as estimated from QCM measurements. (a) $0.05 \mathrm{M} \mathrm{Ce}\left(\mathrm{CH}_{3} \mathrm{COO}\right)_{3}+0.05 \mathrm{M} \mathrm{CH}_{3} \mathrm{COOH}$ at $\mathrm{pH}=5.6$ and $293 \mathrm{~K}$, (b) $0.05 \mathrm{M} \mathrm{Pr}\left(\mathrm{CH}_{3} \mathrm{COO}\right)_{3}+0.05 \mathrm{M} \mathrm{CH}_{3} \mathrm{COOH}$ at $\mathrm{pH}=7.1$ and $293 \mathrm{~K}$.

amount, at a microgram $/ \mathrm{cm}^{2}$ level, by adjusting the reaction time. In the dark state, film formation on the substrate was caused by a local cell mechanism. ${ }^{13}$ More specifically, $\mathrm{Ce}^{3+}$ was oxidized by dissolved oxygen molecules through electron transfer in the Pt substrate, and was immediately transformed into a $\mathrm{CeO}_{2}$ thin film. The $\mathrm{Ce}^{3+}$ in solution was coordinated with up to four acetate ligands; $\mathrm{Ce}^{3+}, \mathrm{Ce}(\mathrm{OH})^{2+}, \mathrm{Ce}(\mathrm{Ac})_{2}{ }^{+}$, $\mathrm{Ce}(\mathrm{Ac})_{2}{ }^{+}, \mathrm{Ce}(\mathrm{Ac})_{3}$, or $\mathrm{Ce}(\mathrm{Ac})_{4}{ }^{-}$, where $\mathrm{Ac}^{-}$indicates an acetate ion $\left(\mathrm{CH}_{3} \mathrm{COO}^{-}\right)$. As reported in the previous paper, ${ }^{14}$ the predominant species in the bath can be calculated from the ionization product of water, the dissociation constant for acetic acid, and the formation constants of the complex ions. As a result, the solution used here $\left(0.05 \mathrm{M} \mathrm{Ce}^{3+}+0.20 \mathrm{M}\right.$ total $\mathrm{Ac}^{-}$at $\left.\mathrm{pH}=5.6\right)$ consisted of $7.6 \% \mathrm{Ce}^{3+}, 0.0 \% \mathrm{Ce}(\mathrm{OH})^{2+}$, $38.2 \% \mathrm{Ce}(\mathrm{Ac})^{2+}, 40.9 \% \mathrm{Ce}(\mathrm{Ac})_{2}{ }^{+}, 11.8 \% \mathrm{Ce}(\mathrm{Ac})_{3}$, and $1.4 \%$ $\mathrm{Ce}(\mathrm{Ac})_{4}{ }^{-}$. The oxidation potentials of $\mathrm{Ce}(\mathrm{Ac})_{\mathrm{x}}{ }^{(3-\mathrm{x}){ }^{+}}(\mathrm{x}=1 \sim 4)$ were shifted to a more positive value than that of uncoordinated $\mathrm{Ce}^{3+}$ due to stabilization by complexing. ${ }^{15}$ Since the potentials were located below the reduction potential of an oxygen molecule under the present conditions (e.g., $E\left(\mathrm{Ce}(\mathrm{Ac})_{2}{ }^{+} / \mathrm{CeO}_{2}(\mathrm{~s})\right)=0.07 \mathrm{~V}<E\left(\mathrm{H}_{2} \mathrm{O} / \mathrm{O}_{2}\right)=0.89 \mathrm{~V}$ vs. $\mathrm{NHE}$, at $p_{\mathrm{O} 2}=0.2$ and $\left.\mathrm{pH}=5.6\right)$, the dissolved oxygen molecules could oxidize the $\mathrm{Ce}^{3+}$ to a higher valence state. The reduction of oxygen and the oxidation of $\mathrm{Ce}^{3+}$ would proceed preferentially on the surface of the Pt substrate, rather than in the solution bulk, due to the high catalytic performance of the $\mathrm{Pt}$ substrate for oxygen reduction. As shown in Fig. 1a, the deposition rate on the $\mathrm{C}$ substrate, which had a low oxygen reduction activity, was slower than on the $\mathrm{Pt}$ substrate. In addition, the open-circuit potential of $\mathrm{Pt}$ shifted gradually lower during the deposition (Fig. 1S in the ESI). Because the $\mathrm{Ce}^{3+}$ to be oxidized was present in abundance, its concentration did not change appreciably over the entire reaction period. Taking into account the small amount of dissolved oxygen, which was responsible for the cathodic reaction, the deposition rate would be limited by the diffusion of oxygen molecules to the Pt surface. Indeed, the open circuit potential in the $\mathrm{O}_{2}$-saturated solution was kept nearly constant during the reaction (Fig. 1S). As a result, the negative shift of the open-circuit potential probably originated from a reduction of the partial current density for the cathodic reaction. These observations support the assumption that a local cell mechanism was responsible for the electroless 
deposition. Because of the lower solubility of the $\mathrm{Ce}^{\mathrm{IV}}$ state than of the reduced state, $\mathrm{Ce}^{\mathrm{IV}}$ would be deposited as a solid phase of $\mathrm{CeO}_{2}$ on the $\mathrm{Pt}$ substrate. The consumption of protons by oxygen reduction, i.e., the generation of hydroxide ions, could increase the local $\mathrm{pH}$ near the $\mathrm{Pt}$ surface and promote the formation of $\mathrm{CeO}_{2} \cdot{ }^{13}$

Crystalline $\mathrm{CeO}_{2}$ behaves as an n-type semiconductor, with a band gap of ca. $3.1 \mathrm{eV}$, which can be excited by irradiation of light with a wavelength shorter than $400 \mathrm{~nm}$. Photoelectrochemical evaluation (Fig. $2 \mathrm{~S}$ in the ESI) established that the deposited layer could act as an n-type semiconductor electrode (i.e., it generated an anodic photocurrent) without post-annealing. From the UV-vis diffuse reflectance spectrum of the film (Fig. $3 \mathrm{~S}$ in the ESI), as-deposited by photoelectroless deposition, the film had an absorption with a shoulder at ca. $400 \mathrm{~nm}$, which is consistent with the band gap energy of $\mathrm{CeO}_{2}$ noted above. ${ }^{16}$ Fig. 1a indicates that photoirradiation strongly enhanced the formation rate of the thin film. Since the dark reaction proceeds via a local cell mechanism, the film growth was suppressed once the substrate was covered with the deposit, which is a poor conductor. On the other hand, UV irradiation to the substrate caused band gap excitation of the pre-formed $\mathrm{CeO}_{2}$ particles, producing electrons and holes in the conduction and valence bands, respectively. Since the oxidation potential of $\mathrm{Ce}^{3+}$ coordinated with acetate ions is above the upper level of the valence band, $\mathrm{Ce}^{3+}$ was oxidized by the holes and the $\mathrm{CeO}_{2}$ particles continued to grow under the irradiation. Oxidation may have also proceeded via $\mathrm{OH}$ radicals produced as a result of the reaction between holes and water molecules. The excited electrons could reduce oxygen molecules in the solution. Since the $\mathrm{CeO}_{2}$ nuclei acted as photoabsorbers and reaction sites for oxidation, film growth occurred without electron transport through the Pt substrate, and rapid deposition was accomplished. As shown in Fig. 1a, however, the growth curve gradually became less steep even under UV light irradiation, suggesting the consumption of dissolved oxygen and presumably the slower oxygen reduction on $\mathrm{CeO}_{2}$ than on Pt. In summary, it was confirmed that UV light irradiation assisted $\mathrm{Ce}^{3+}$ oxidation and accelerated the film growth significantly. We have also confirmed that photoelectroless deposition is possible even on a non-conductive substrate after an activation treatment to deposit a Pd catalyst, which is similar to the electroless plating of metal layers.

Fig. 2 shows the influence of $\mathrm{Ce}^{3+}$ concentration on the electroless deposition amount. In the dark reaction, the deposition amount was slightly increased in the concentrated solution. On the other hand, the photoelectroless deposition was largely suppressed by an increase in $\left[\mathrm{Ce}^{3+}\right]$, and the deposited amount was less than that for the dark reaction at $0.20 \mathrm{M}$. This may be explained by a photo-reductive dissolution of $\mathrm{CeO}_{2} \cdot{ }^{17}$ Under irradiation by a photon energy significantly exceeding the band gap of $\mathrm{CeO}_{2}$, the photogenerated electrons trapped at the $\mathrm{CeO}_{2} /$ solution interface reduced the surface $\mathrm{Ce}^{4+}$. This was followed by dissolution of the reduced species $\left(\mathrm{Ce}^{3+}\right)$, which have a higher solubility. As the amount of dissolved oxygen decreased, the

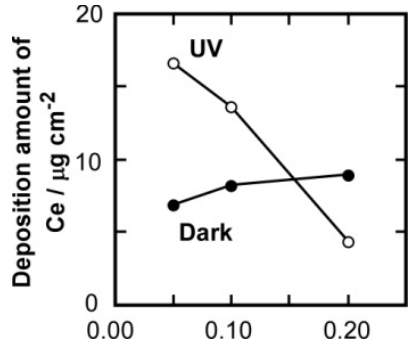

Fig. 2 Effect of $\mathrm{Ce}^{3+}$ concentration on the deposition amount of $\mathrm{Ce}$ on a Pt substrate at $313 \mathrm{~K}$ for $24 \mathrm{~h}$, with an identical molar amount of acetic acid to that of $\mathrm{Ce}^{3+}$ added to the solution.

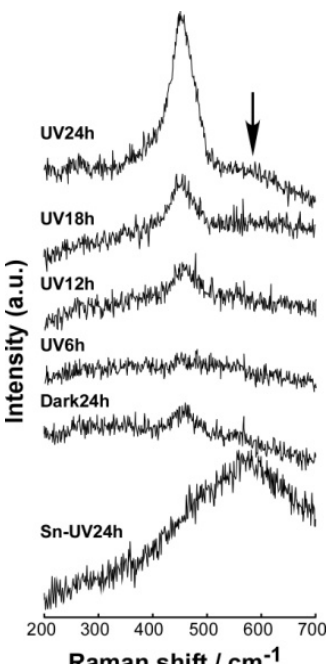

Raman shift $/ \mathrm{cm}^{-1}$

Fig. 3 Raman spectra of thin films deposited over various reaction times in $0.05 \mathrm{M} \mathrm{Ce}\left(\mathrm{CH}_{3} \mathrm{COO}\right)_{3}+0.05 \mathrm{M} \mathrm{CH}_{3} \mathrm{COOH}$ at $\mathrm{pH}=5.6$ and $313 \mathrm{~K}$. The spectrum of the film fabricated in $0.05 \mathrm{M} \mathrm{SnSO}_{4}$ solution at $293 \mathrm{~K}$ for $24 \mathrm{~h}$ is also displayed (Sn-UV24h).

excited electrons were consumed by the reduction of $\mathrm{Ce}^{4+}$ rather than dissolved oxygen molecules. Our previous paper revealed that the presence of carboxylate anions promoted the photo-reductive dissolution of iron oxides by trapping holes produced in the valence band. ${ }^{8}$ In the present study, under a high $\left[\mathrm{Ce}^{3+}\right]$, i.e., a high acetate ion concentration, the effect of photo-reductive dissolution became remarkable, and decreased the deposition amount. Under our experimental conditions, the photo-assisted effect on the electroless deposition of $\mathrm{CeO}_{2}$ thin films was most evident in dilute solution.

The crystal structure of the prepared films was studied using XRD and Raman spectroscopy. The XRD patterns of asdeposited thin films included a very weak diffraction peak attributed to the (111) plane of the fluorite crystal structure of $\mathrm{CeO}_{2}$ (Fig. 4S in the ESI). In order to investigate the crystallinity of the film in more detail, Raman spectroscopy was performed for films prepared with various reaction times, as shown in Fig. 3. The main peak at $452 \mathrm{~cm}^{-1}$ observed in all spectra (excluding the "Sn-UV $24 \mathrm{~h}$ ") corresponds to the triply-degenerate Raman active $F_{2 g}$ mode of the fluorite structure, which was detected as a symmetric breathing mode of oxygen atoms surrounding cations. ${ }^{18}$ The peak height increased with increasing reaction time, implying the sustainable growth of a $\mathrm{CeO}_{2}$ film during the photoelectroless 

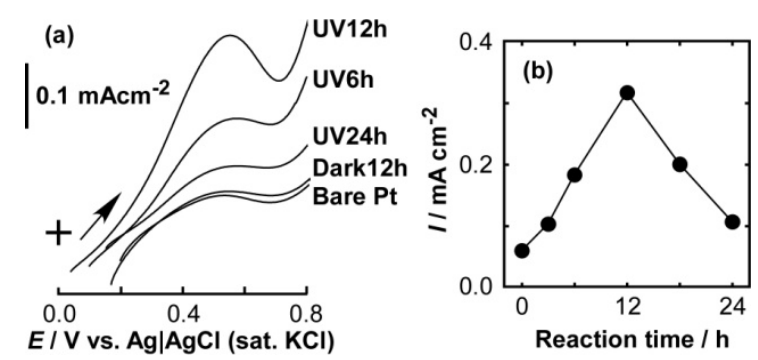

Fig. 4 (a) Anodic polarization curves $\left(5 \mathrm{M} \mathrm{CH}_{3} \mathrm{OH}+0.1 \mathrm{M} \mathrm{K}_{2} \mathrm{SO}_{4}\right.$ solution) of bare $\mathrm{Pt}$ and $\mathrm{Pt} / \mathrm{CeO}_{2}$ electrodes prepared by dark- or photoelectroless (UV) deposition for various reaction times. (b) Reaction time dependence of the anodic peak current density $(I)$ corresponding to methanol oxidation at $E=+0.55 \mathrm{~V}$ vs. $\mathrm{Ag} \mid \mathrm{AgCl}$ (sat. $\mathrm{KCl}$ ).

deposition. The small discrepancy of the peak wavenumber for the bulk $\mathrm{CeO}_{2}$ crystal $\left(464 \mathrm{~cm}^{-1}\right)$ suggests that the film was composed of tiny primary crystallites of nanometer dimensions, where the crystallite size calculated using the Raman line width (UV24h in Fig. 3) and the emprical equation given by Kosacki et al. was ca. $3 \mathrm{~nm} .{ }^{19}$ The small hump at the larger Raman shift (ca. $570 \mathrm{~cm}^{-1}$, indicated by an arrow) corresponds to oxygen defects due to the partial reduction of $\mathrm{Ce}^{4+} \cdot{ }^{20}$ In contrast, the film prepared by the dark reaction showed only a small peak, even after $24 \mathrm{~h}$ of reaction. These results confirm that UV irradiation during the electroless deposition is effective for the fabrication of crystalline $\mathrm{CeO}_{2}$ films without post-treatment.

It has been reported that $\mathrm{Pt} / \mathrm{CeO}_{2} / \mathrm{C}$ composites show excellent electrocatalytic performance for the direct oxidation of alcohol. ${ }^{12}$ Therefore, the electrocatalytic activity of the asdeposited $\mathrm{CeO}_{2}$ films was evaluated by measuring their anodic polarization curves in methanol solution at $298 \mathrm{~K}$. Fig. 4a shows the polarization curves of $\mathrm{CeO}_{2}$ films on $\mathrm{Pt}$, fabricated under illumination or in the dark for various reation durations. Due to the adsorption of $\mathrm{CO}$ on the Pt surface, the bare Pt showed no oxidation activity. On the other hand, the Pt electrodes covered with photodeposited $\mathrm{CeO}_{2}$ (UV) showed an anodic current peak at ca. $+0.55 \mathrm{~V}$. These results indicate that the $\mathrm{CeO}_{2}$ on the Pt surface reduces the overpotential for $\mathrm{CO}$ oxidation. Takahashi and coworkers proposed that the active oxygen species produced by interactions between oxygen vacancies in the $\mathrm{CeO}_{2}$ surface and water molecules promotes the oxidation of $\mathrm{CO}^{21}$ Consequently, the $\mathrm{CeO}_{2}$ thin film containing oxygen vacancies, which were detected by Raman spectroscopy, contributed to the anodic oxidation current observed in Fig. 4a. On the contrary, the polarization curve of the film prepared in the dark was nearly identical to that of the bare Pt substrate, indicating a lower activity for the anodic oxidation of methanol due to a small depostion amount (Fig. 1a). Fig. $4 \mathrm{~b}$ plots the anodic peak current at $+0.55 \mathrm{~V}$ as a function of the photoelectroless deposition time. In the figure, the peak current rises with increasing reaction time and reaches a maximum at $12 \mathrm{~h}$. These results are consistent with the observed film morphology. Fig. 5 shows SEM images of films formed under various conditions. The film prepared in the dark for $24 \mathrm{~h}$ (Fig. 5a) had no distinct particles. The observed small pores may have provided diffusion paths for oxygen molecules to be reduced at the $\mathrm{Pt}$ surface.
Photoelectroless
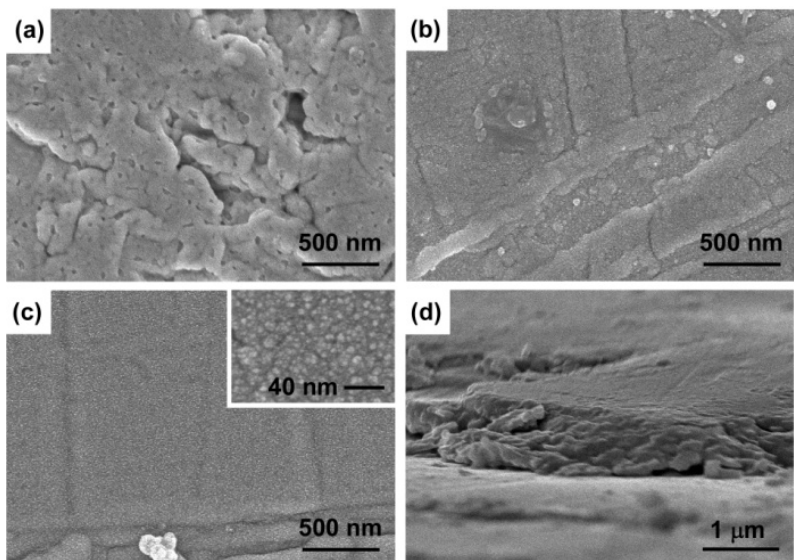

Fig. 5 Surface SEM images of as-deposited thin films deposited under dark conditions for $24 \mathrm{~h}$ (a) and under UV illumination for $12 \mathrm{~h}$ (b) or 24 $\mathrm{h}(\mathrm{c})$. Cross-sectional image of (c) is also displayed in (d).

deposition for $24 \mathrm{~h}$ (Fig. $5 \mathrm{c}$ and d) resulted in the formation of a relatively smooth film (thickness $<1 \mu \mathrm{m}$ ) composed of small particles with diameters of a few $\mathrm{nm}$ (inset in Fig. 5c). This supports the idea that the film growth proceeds homogeneously on the surface of the $\mathrm{CeO}_{2}$ particles, rather than at the Pt surface under the UV light irradiation. A relatively bumpy surface that may have reflected the surface roughness of the $\mathrm{Pt}$ substrate was observed in the film prepared for $12 \mathrm{~h}$ (Fig. 5b). In contrast, a smooth and dense microstructure was observed after $24 \mathrm{~h}$ of reaction (Fig. 5c), as noted previously. The oxidation of methanol and oxidative removal of $\mathrm{CO}$ adsorbed on the $\mathrm{Pt}$ surface should occur at the three-phase boundary between $\mathrm{Pt}, \mathrm{CeO}_{2}$, and the methanol solution. For deposition times over $12 \mathrm{~h}$, the thick, dense $\mathrm{CeO}_{2}$ film could act as a barrier against methanol penetration toward the three-phase boundary. Consequently, even though the anodic current was increased by $\mathrm{CeO}_{2}$ deposition at the initial stage, the electrocatalytic activity of the film diminished with increasing reaction time after $12 \mathrm{~h}$. On the other hand, due to poor crystallinity or a lower deposition amount, films fabricated by the dark reaction had no electrocatalytic activity. Therefore, $\mathrm{CeO}_{2}$ films deposited by photoelectroless deposition were capable of electrocatalytic methanol oxidation without any post-treatment. The activity depended upon film morphology and crystallinity. A dense, thick film formed after a longer deposition time, as shown in Fig. 5c, and appeared to act as an efficient barrier layer against the penetration of electrolytes. Hence, the dense $\mathrm{CeO}_{2}$ thin films prepared here may be adopted as anti-corrosion layers to protect structural materials, because $\mathrm{CeO}_{2}$ is harmless and has a self-healing ability similar to conventional chromate barrier coatings. ${ }^{22}$

The rare-earth element $\mathrm{Pr}^{3+}$ can also be oxidized to a higher valence, and then transformed into an insoluble oxide. Therefore, the photoelectroless deposition of $\operatorname{Pr}^{\mathrm{IV}}$ oxide was carried out in a $\operatorname{Pr}\left(\mathrm{CH}_{3} \mathrm{COO}\right)_{3}$ solution with an acetic acid additive. According to the literature, ${ }^{23} \mathrm{Pr}^{3+}$ can be oxidized to the $\mathrm{Pr}^{\mathrm{IV}}$ state at $\mathrm{pH}>6$, so the $\mathrm{pH}$ of the solution was adjusted 
to ca. 7. Fig. $1 \mathrm{~b}$ shows the variation of the deposition weight during photo- and dark-electroless deposition. UV light irradiation clearly accelerated the film formation. XRD analysis of the obtained films revealed the presence of a crystalline $\operatorname{Pr}_{6} \mathrm{O}_{11}$ phase. We also investigated the possibility of photoelectroless deposition of $\mathrm{Sn}^{\mathrm{IV}}$ oxide, which also behaves as an n-type semiconductor with a band gap of $3.5 \mathrm{eV}$ and has many important applications, such as sensors and transparent electrodes. ${ }^{24}$ In this case, an acidic $\mathrm{SnSO}_{4}$ solution was employed in order to stabilize $\mathrm{Sn}^{2+}$ in the solution. The influence of UV irradiation on film formation was stronger than for Ce or Pr. While no deposition occurred in the dark, UV light irradiation caused the deposition of a blue, transparent film. The Raman spectrum of the film (Sn-UV24h in Fig. 3) included a broad band assigned to $\mathrm{Sn}^{\mathrm{IV}}$ hydrous oxide. ${ }^{25}$ However, deposition of the film was possible not only on a Pt substrate but also on other non-conductive substrates, such as quartz glass and alumina ceramics, suggesting that the formation mechanism of the film in $\mathrm{SnSO}_{4}$ solution was dissimilar to the photoelectroless deposition of $\mathrm{CeO}_{2}$. Recently, it has been reported that UV light irradiation of a $\mathrm{Sn}^{2+}$ solution induces the production of mesoporous $\mathrm{SnO}_{2}$ particles at the solution - air interface. ${ }^{26}$ In this case, the photo-assisted disproportionation of $\mathrm{Sn}^{2+}$ produces $\mathrm{Sn}^{0}$ and $\mathrm{Sn}^{4+}$. The $\mathrm{Sn}^{4+}$ is hydrolyzed to produce insoluble $\mathrm{H}_{2} \mathrm{SnO}_{3}$, which decomposes into $\mathrm{SnO}_{2}$ during drying. On the other hand, the reduced species $\left(\mathrm{Sn}^{0}\right)$ is oxidized to $\mathrm{SnO}_{2}$ at the air solution interface. Consequently, thin film deposition seems to occur through a photochemical reaction rather than a local cell mechanism. Therefore, photoirradiation during electroless deposition may be effective for other kinds of semiconductor oxide thin films.

\section{Conclusions}

The present study investigated the effect of UV light irradiation on the electroless deposition of several n-type semiconductor thin films (Ce, $\mathrm{Pr}$, and $\mathrm{Sn}$ oxide). For $\mathrm{CeO}_{2}$, the formation mechanism of oxide thin films was explained by a local cell mechanism involving electron transfer at the $\mathrm{Pt}$ substrate. Specifically, dissolved oxygen acted as an oxidizer of the metal ions, and the oxidized metal species were deposited as an insoluble oxide film on the substrate. UV light irradiation enhanced the deposition rate and the density of the film, indicating that the photocarriers, which were produced in pre-formed oxide nuclei by the UV light excitation, photocatalytically promoted the reduction of dissolved oxygen and the oxidation of metal ions. The deposition rate was also affected by the concentration of reactant; that is, a high concentration resulted in a decrease of the deposition amount due to photoreductive dissolution. The obtained $\mathrm{Pt} / \mathrm{CeO}_{2}$ thin films demonstrated varying activities for the electrocatalytic oxidation of methanol. This activity depended heavily on the porosity and crystallinity of the films, which could be controlled by the deposition time. On the other hand, it was confirmed that $\operatorname{Pr}_{6} \mathrm{O}_{11}$ and $\mathrm{Sn}^{\mathrm{IV}}$ hydrous oxide thin films were also formed by UV irradiation of $\mathrm{Pr}^{3+}$ and $\mathrm{Sn}^{2+}$ solutions, respectively, and the deposition of $\mathrm{Sn}^{\text {IV }}$ hydrous oxide proceeded through a photochemical reaction initiated by the disproportionation of $\mathrm{Sn}^{2+}$. In addition to $\mathrm{Ce}, \mathrm{Pr}$, and $\mathrm{Sn}$, there are many other semiconductor oxides that can be formed by the anodic oxidation of metal ions of lower valence $\left(\mathrm{TiO}_{2}\right.$, etc.). The same photo-assisted effect is expected for the electroless deposition of these oxides on various conducting and non-conducting substrates. Moreover, the photochemical technique enables on-site fabrication, because the reaction is enhanced only within the irradiated area. The present technique should be useful in the fabrication of many different kinds of metal oxide and complex oxide thin films.

\section{Acknowledgements}

The present study was partly supported by Special Coordination Funds for Promoting Science and Technology, MEXT, Japan: "The Nagasaki University Strategy for Fostering Young Scientists".

\section{Notes and references}

${ }^{a}$ Department of Materials Science and Engineering, Faculty of Engineering, Nagasaki University, Nagasaki 852-8521, Japan. Fax: 81 95 8192667; Tel: 8195 8192667; E-mail: kkamada@nagasaki-u.ac.jp

$\dagger$ Electronic Supplementary Information (ESI) available: Figures showing change of open circuit potential during electroless deposition of $\mathrm{CeO}_{2}$, photoelectrochemical property, UV-Vis reflectance spectra and XRD patterns of $\mathrm{CeO}_{2}$ films. See DOI: 10.1039/b000000x/

1 K. Bernhard and A.J. Bard, J. Am. Chem. Soc., 1978, 100, 43174318; S. Sato, A. Sobczynski, J.M. White, A.J. Bard, A. Campion, M.A. Fox, T.E. Mallouk and S. E.; Webber, J. Photochem. Photobiol. A, 1989, 50, 283-290.

2 T. Torimoto, J. Paz Reyes, K. Iwasaki, B. Pal, T. Shibayama, K. Sugawara, H. Takahashi and B. Ohtani, J. Am. Chem. Soc., 2003, 125, 316-317; T. Torimoto, H. Kontani, Y. Shibutani, S. Kuwabata, T. Sakata, H. Mori and H. Yoneyama, J. Phys. Chem. B, 2001, 105, 6838-6845.

3 R.C. Hayward, D.A. Saville and I.A. Aksay, Nature, 2000, 404, 5659.

4 S. Nakanishi, T. Tanaka, Y. Saji, E. Tsuji, S. Fukushima, K. Fukami, T. Nagai, R. Nakamura, A. Imanishi and Y. Nakato, J. Phys. Chem. C, 2007, 111, 3934-3937; A. Tsujiko, T. Kisumi, Y. Magari, K. Murakoshi and Y. Nakato, J. Phys. Chem. B, 2000, 104, 4873-4879.

5 H. Masuda, K. Kanezawa, M. Nakao, A. Yokoo, T. Tamamura, T. Sugiura, H. Minoura and K. Nishio, Adv. Mater., 2003, 15, 159-161; T. Oekermann, T. Yoshida, J. Nakazawa, S. Yasuno, T. Sugiura and H. Minoura, Electrochim. Acta, 2007, 52, 4325-4333.

6 C. Scheck, Y.-K. Liu, P. Evans, R. Schad, A. Bowers, G. Zangari, J.R. Williams and T.F. Issacs-Smith, Phys. Rev. B 2004, 69, 3533435341; J.A. Switzer, J. Electrochem. Soc., 1986, 133, 722-728; Y. Matsumoto, M. Noguchi and T. Matsunaga, J. Phys. Chem. B, 1999, 103, 7190-7194; M. Takahashi, M. Todorobaru, K. Wakita and K. Uosaki, Appl. Phys. Lett., 2002, 80, 2117-2119; Y. Sugimoto and L.M. Peter, J. Electroanal. Chem., 1995, 386, 183-188; K. Murase, M. Matsui, M. Miyake, T. Hirato and Y. Awakura, J. Electrochem. Soc., 2003, 150, C44-C51.

7 K. Kamada, K. Higashikawa, M. Inada, N. Enomoto and J. Hojo, J. Phys. Chem. C, 2007, 111, 14508-14513.

8 K. Kamada, T. Hyodo and Y. Shimizu, J. Phys. Chem. C, 2010, 114, 3707-3711.

9 Z. Shao and S.M. Haile, Nature, 2004, 431, 170-173.

10 T. Masui, M. Yamamoto, T. Sakata, H. Mori and G.-y. Adachi, J. Mater. Chem., 2000, 10, 353-357; T. Masui, H. Hirai, R. Hamada, N. Imanaka, G.-y. Adachi, T. Sakata and H. Mori, J. Mater. Chem., 2003, 13, 622-627; M. Yamashita, K. Kameyama, S. Yabe, S. Yoshida, Y. Fujishiro, T. Kawai and T. Sato, J. Mater. Sci., 2002, 37, 683-687. 
11 H. Ardelean, I. Frateur and P. Marcus, Corr. Sci., 2008, 50, 19071918; Y. Hamlaoui, F. Pedraza and L. Tifouti, Corr. Sci., 2008, 50, 2182-2188.

12 C. Xu and P.K. Shen, Chem. Comm., 2004, 2238-2239; C. Xu, P.K. Shen and Y. Liu, J. Power. Sources, 2007, 164, 527-531; C.L. Campos, C. Roldán, M. Aponte, Y. Ishikawa and C.R. Cabrera, J. Electroanal. Chem., 2005, 581, 206-215.

13 M.A. Arenas and J.J. de Damborenea, Electrochim. Acta, 2003, 48, 3693-3698.

14 E.A. Kulp, S.J. Limmer, E.W. Bohannan and J.A. Switzer, Solid State Ionics, 2007, 178, 749-757.

15 A.Q. Wang and T.D. Golden, J. Electrochem. Soc., 2003, 150, C616C620; T.D. Golden and A.Q. Wang, J. Electrochem. Soc., 2003, 150, C621-C624.

16 X.-H. Lu, X. Huang, S.-L. Xie, D.-Z. Zheng, Z.-Q. Liu, C.-L. Liang and Y.-X. Tong, Langmuir, 2010, 26, 7569-7573; G.-R. Li, D.-L. Qu, L. Aruraut and Y.-X. Tong, J. Phys. Chem. C, 2009, 113, 1235-1241.

17 M.I. Litter and M.A. Blesa, J. Colloid Interface Sci., 1988, 125, 679687; M. Grätzel, J. Kiwi, C.L. Morrison, R.S. Davidson and A.C.C. Tseung, J. Chem. Soc. Faraday Trans., 1985, 81, 1883-1890

18 M.-F. Luo, Z.-L. Yan, L.-Y. Jin and M. He, J. Phys. Chem. B, 2006, 110, 13068-13071; S. Kanakaraju, S. Mohan and A.K. Sood, Thin Solid Films, 1997, 305, 191.

19 F. Zhang, S.-W. Chan, J.E. Spanier, E. Apak, Q. Jin, R.D. Robinson and I.P. Herman, Appl. Phys. Lett. 2002, 80, 127-129; I. Kosacki, T. Suzuki, H.U. Anderson and P. Colomban, Solid State Ionics 2002, 149, 99-105.

20 H. Takamura and N. Takahashi, Solid State Ionics, 2010, 181, 100103.

21 M. Takahashi, T. Mori, F. Ye, A. Vinu, H. Kobayashi and J. Drennan, J. Am. Ceram. Soc., 2007, 90, 1291-1294; M. Takahashi, T. Mori, A. Vinu, H. Kobayashi, J. Drennan and D.-R. Ou, J. Mater. Res., 2006, 21, 2314-2322.

22 M.A. Arenas and J.J. de Damborenea, Surf. Coatings Tech., 2004, 187, 320-325; M.G.S. Ferreira, R.G. Duarte, M.F. Montemor and A.M.P. Simões, Electrochim. Acta, 2004, 49, 2927-2935; W.G. Fahrenholtz, M.J. O'Keefe, H. Zhou and J.T. Grant, Surf. Coatings Tech., 2002, 155, 208-213; K. Aramaki, Corros. Sci., 2004, 46, 15651579.

23 M. Pourbaix, in Atlas of Electrochemical Equilibria in Aqueous Solutions; National Association of Corrosion Engineers: Houston, Texas, 1974, pp. 193.

24 S.-L. Chou, J.-Z. Wang, H.-K. Liu and S.-X. Dou, Electrochem. Comm., 2009, 11, 242-246; S.T. Chang, I.C. Leu and M.H. Hon, J. Cryst. Growth, 2004, 273, 195-202.

25 M. Ristić, M. Ivanda, S. Popović and S. Musić, J. Non-Cryst. Solids, 2002, 303, 270-280.

26 H. Wang, F. Sun, Y. Zhang, L. Li, H. Chen, Q. Wu and J.C. Yu, J. Mater. Chem., 2010, 20, 5641-5645; M. Ichimura, K. Shibayama and K. Masui, Thin Solid Films, 2004, 466, 34-36. 